QUADERNS DE FILOSOFIA VOL. I NÚM. 2 (20 I 4): I I-33

ISSN: 234I-I 4I 4 DOI: IO.7203/QFIA.I.2.4IIO

JoRge MitTELMANN

Universidad de los Andes. Chile

\title{
¿Una imagen dualista en el De Anima de Aristóteles? ${ }^{1}$
}

Recibido: 6/5/14. Aceptado: 20/5/14

Resumen: El artículo aborda una contradicción aparente en la caracterización aristotélica del alma, que podría perjudicarla seriamente. Aun cuando este definiens suele considerarse como una formulación no-dualista de las funciones vitales, fundada en una aproximación hilemórfica a los seres vivientes, Aristóteles continúa refiriéndose al cuerpo en términos instrumentales y lo caracteriza, de modo consistente, como una herramienta del alma. Se argumenta que este modo filosófico de expresión debe tomarse en serio, y que no puede descartarse como un mero rasgo estilístico o como un residuo teórico de los días en que Aristóteles frecuentaba la Academia. Mediante el examen de la recepción neoplatónica y peripatética de la analogía del alma con un tripulante, el artículo concluye que la consideración de los cuerpos orgánicos como "instrumentos" no implica compromisos ontológicos indeseados con almas individuales concebidas como sus usuarios.

Abstract: This paper deals with a seeming contradiction that may seriously impair Aristotle's definition of the soul in his De Anima. While this definiens has been widely regarded as providing a non-dualistic account of life-functions, grounded in a hylomorphic approach to living beings, Aristotle sticks to an instrumental language vis-à-vis the body, which he consistently refers to as a tool of the soul. It is argued that this philosophical way of talking should be taken at face value, without dismissing it as a stylistic feature or a theoretical hangover from Aristotle's Platonic days.

${ }^{1}$ Algunas secciones de este artículo aparecieron, en una versión sensiblemente diversa, en mi artículo "Neoplatonic Sailors and Peripatetic Ships: Aristotle, Alexander and Philoponus" (Journal of the History of Philosophy, 51, no 4 (2013): 545-66). El presente texto fue redactado en el marco del Proyecto Fondecyt (Chile), no 1130365. 
By paying close attention to the Peripatetic and Neoplatonic reception of the "soul - boatman analogy", the paper concludes that organic bodies may be considered as instrumental in nature, without this entailing commitment to further individual souls conceived as "users".

Palabras clave: Alma, vida, cuerpo, psicología, Aristóteles, neoplatonismo.

Keywords: Soul, life, body, hylomorphism, psychology, Aristotle, Neoplatonism.

\section{INTRODUCCIÓN}

Z l capítulo inicial de De Anima II, en el que Aristóteles esboza una ca-

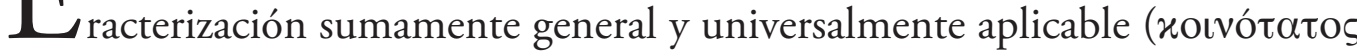
$\lambda$ ó $\gamma$ s) del tipo de entidad que es el 'alma', se cierra con una comparación desconcertante, que parece contradecir el tenor de esa definición inicial. En efecto, tras argumentar cuidadosamente que la relación 'cuerpo-alma' es una instancia del vínculo hilemórfico, al que deben su unidad substancial todos los entes naturales, Aristóteles escribe: "además resulta incierto (ádelon) si de este modo es el alma la actualidad de un cuerpo, [a saber], como el piloto lo es de la nave" (413a8-9). Esta observación parece sugerir que, lejos de hallarse en el cuerpo como aquello que informa su materia, el alma lo habita al modo de un ocupante cuyas condiciones de identidad y persistencia difieren obviamente de las del cuerpo ocupado. Baste señalar en tal sentido que, mientras la presencia ininterrumpida del piloto no es condición necesaria para la existencia de la nave, Aristóteles afirma en diversos pasajes que un cuerpo sin alma ya no es digno de ese nombre. ${ }^{2}$ Esta sola diferencia parece acreditar la insuficiencia de la analogía náutica, lo que vuelve llamativo que Aristóteles la considere como una opción teórica todavía viable y digna de examen a esas alturas del capítulo. En lugar del pronóstico "incierto” que Aristóteles reserva a la imagen del piloto en el navío, las consideraciones precedentes debiesen conducirle a descartar esa comparación como inadecuada.

Ello explica la perplejidad de los principales traductores y comentaristas del tratado ante la aparente intrusión de una analogía dualista ${ }^{3}$ en el seno de una argumentación que se propone subrayar la unidad substancial de cuerpo y

${ }^{2}$ Cf. De Anima II 1, 412b20-25; De gen. an. I 19, 726b22-24; II 1, 734b24-27; 735a5-8; Meteorologica IV 12, 389b 30-31; Politica I, 1253a19-25; Metaph. Z 10, 1035b14-18; Z 11, 1036b30-2; De part. an. I 1, 641a3-5.

3 Se entiende aquí "dualismo" en su sentido lato, como la postulación de dos entidades numéricamente diversas de cuya cohabitación resulta una cierta unidad psicosomática — por ejemplo, "este hombre" o "este caballo", para atenerse a los ejemplos de Categorías 1b4-5-. 
alma. ${ }^{4}$ El talante poco dualista de dicha argumentación parece confirmarse si se atiende a las precisiones que Aristóteles introduce inmediatamente después de enunciar su "fórmula común". Como si se propusiera aclarar cuál es su alcance, el Estagirita advierte contra el riesgo de "reificar" el alma preguntando, por ejemplo, si ella y su cuerpo constituyen algo uno, o son más bien la adición de dos cosas diferentes (412b6-8). Como se sabe, Aristóteles reduce al absurdo esa inquietud, comparándola con la de quien preguntara si la cera y la figura que ella exhibe constituyen algo uno y, en general, "la materia de cada cosa y aquello de lo cual ella es materia" (412b8). Ahora bien, resulta obviamente inconsistente comparar el alma, a la vez, con la figura de un cuerpo (412b7) y con el tripulante de una embarcación (413a9), pues la segunda comparación da a entender que alma y cuerpo son dos cosas diferentes, en tanto que la primera sugiere más bien que no lo son. De este modo, las líneas conclusivas del capítulo ponen en entredicho los resultados obtenidos en el resto de él, en la medida en que el símil del piloto reintroduce una substancia separada, allí donde la noción de "entelequia" o actualidad primera no dejaba espacio conceptual para la adición de un tripulante, y parecía superar el dualismo del Fedón.

Supuesto que ésa sea su última palabra, Aristóteles habría incurrido en el error categorial de convertir la función náutica en el primer tripulante de una embarcación. Uno debe preguntarse, empero, si es razonable imputarle sin más esa confusión, o bien cabe intentar lecturas alternativas que vuelvan compatibles ambas posiciones prima facie inconsistentes. Como veremos, el núcleo de la dificultad está insinuado ya en la definición preliminar del alma, en la que Aristóteles alude a un cuerpo vivo en potencia (412a27-28) para volver

En esta acepción amplia, el dualismo es neutral respecto de la homogeneidad o heterogeneidad ontológica de las dos entidades que se acoplan para constituir un compuesto sensible. Así, aunque la imagen del piloto en el navío suele adscribirse unívocamente a "un dualisme extrême qui correspond à une tendance plus ou moins platonicienne" (MANZINI 2003, 168), dicha analogía puede ser funcional también a una psicología corporeista, como lo indican los argumentos de Alejandro de Afrodisia contra los estoicos (cf. De Anima 20.26 - 21.21), significativamente retomados por Plotino (cf. IV.3.20-22, cuya probable conexión con De Anima 13.9 - 15.26 advirtió H. J. Blumenthal i 968; cf. K. Corrigan I999, 125, n. 30). La viabilidad conceptual de un dualismo corporeísta queda acreditada también por algunas propuestas contemporáneas, que instauran un dualismo psicológico entre entidades fundamentalmente homogéneas desde el punto de vista ontológico, como podrían serlo un organismo y su cerebro. En efecto, en discusiones recientes se ha hecho referencia a este órgano privilegiado como a un 'ocupante' del cuerpo, y se ha propuesto distinguir (para efectos de deontología médica) entre cuerpos 'ocupados' y 'no-ocupados' (cf. J. McMahan i 999, discutido críticamente por A. Gómez-Loвo 2008). Este modo de hablar evoca inmediatamente la relación entre un piloto y su navío, aunque ciertamente no en el contexto de un dualismo sustancial entre un cuerpo y un alma ontológicamente heterogéneos.

${ }^{4}$ Cf. p. ej. Hicks (1907, 319-21); Rodier (I900, 187); Ross (1961, 214-15); Hamlyn (I968, 87); Polansky (2007, 168). Cf. también Tracy (1982, 97-8). 
enseguida sobre esa formulación y reemplazarla por 'cuerpo natural de indole instrumental' —o, si se prefiere, 'cuerpo natural orgánico' (412b5-6) - El alma es, pues, la actualidad primera de un cierto tipo de instrumento. Ahora bien, si se tiene en cuenta que, al menos desde el Primer Alcibiades, ${ }^{5}$ un rasgo esencial de la relación entre usuario e instrumento es la mutua alteridad de ambos relata, se comprende que la conceptualización del cuerpo como un instrumento (órganon) instituya ya de entrada un hiato entre éste y su alma. Cabe preguntarse incluso si la transferencia del esquema de análisis "usuario/ instrumento" al examen del binomio "alma/cuerpo" no es inapropiada para un autor que (según se presume) intenta subrayar la inextricable implicación de toda actividad anímica en una estructura fisiológica. ${ }^{6}$ En la medida en que tales estructuras ofician de instrumentos para las operaciones del alma, a ellas se aplicará el razonamiento inductivo a partir del cual Sócrates muestra que "usuario y útil parecen ser siempre cosas diferentes" (129d11, cf. 129d1). En dicho pasaje del Alcibiades, Sócrates se apoya en la obvia distinción entre un zapatero y sus herramientas, o un músico y su instrumento, para extender enseguida esa alteridad a las partes del cuerpo comprometidas en la ejecución de esos oficios. Puesto que el zapatero se sirve no solo del trinchete para cortar la suela, sino también de sus manos, de sus ojos y, en general, de todo su cuerpo -el cual Aristóteles considerará también como un instrumento complejo, constituido en vistas de una "praxis multiforme" (PA, 645b16-17)— Sócrates concluye, primero, que el hombre es una cosa diferente de su propio cuerpo (129e8), y enseguida que cada hombre es idéntico al usuario que domina este instrumento (tò tồ sómatos árchon), es decir, a su alma (130c3). ${ }^{7}$ Es desde esta perspectiva que resultaría coherente quizás afirmar que el alma está en el cuerpo como un piloto en su navío; ${ }^{8}$ el punto es que dicha perspectiva no parece ser la de Aristóteles, cuya psicología hilemórfica suele interpretarse como

${ }^{5}$ Cf. Alcibiades 129c-130d. (En mi empleo de este pasaje soy especialmente deudor de S. MeNN 2002, a cuyo ensayo remito para una exposición acabada de los rendimientos dualistas de la relación usuario-instrumento.)

${ }^{6}$ De Sensu 1, 436 a5-11; b2-8; DA Г 10, 433b19-20; DA A 1, 403a24-b12; Metaph. Z 10, 1035b14-16; DA B 1, 412b9-11; B 2, 414b19-25. A propósito de la necesaria imbricación material de ciertas formas, cf. también Metaph. E 1, 1025b30 - 1026a6; Z 11, 1036b3-4; 1036b22-32; Physica A 3, 186b21-23; B 9, 200b7-8.

${ }^{7}$ Cf. Denyer (200I, 213-4, ad 129d4-5), quien observa que el paralelismo entre los instrumentos del oficio y las manos del zapatero "soon leads to the idea that we may talk of bodily parts themselves as tools or órgana".

${ }^{8}$ Algunas referencias de Platón al "piloto" ocurren en contextos ético-políticos, donde lo relevante es el gobierno recto de la propia vida, de la vida colectiva o aun del Universo (cf. Pol. 272d6 - e6; cf. Pol. 297e8-12; Rep. VI, 488a2 - 489b); sin embargo, la mayor parte de las alusiones platónicas se limitan a alinearlo junto al médico o al maestro de gimnasia, "como modelo de competencia técnica” o de saber profesional (cf. Santa Cruz (ı 988, 589, n. 99, ad 297e12), 
una superación del dualismo implícito en esta caracterización instrumental del cuerpo. $^{9}$

El desafío más apremiante parece ser, entonces, el de explicar la persistencia de esa caracterización en el definiens del alma, preservando a la vez la intuición hilemórfica central, de acuerdo con la cual la materia y la forma de un viviente no son dos objetos diferentes, sino algo así como el anverso y reverso de una única moneda. Tal parece haber sido, además, la comprensión madura que alcanzó Aristóteles en Metafísica H 6, donde sostuvo que, en el momento de su actualización, la materia de una cosa y la forma que la actualiza "son uno y lo mismo", lo que vuelve superfluo inquirir por la causa de su unidad (1045b18-19). ${ }^{10}$ Ahora bien, como hemos visto en estas indicaciones preliminares, al hablar de la materia próxima del viviente — esto es, de su propio cuerpo- como de un instrumento, Aristóteles reintroduce una alteridad precisamente allí donde su teoría hilemórfica la excluye.

Desde el punto de vista conceptual, dos caminos prima facie transitables podrían conducir a una armonización eventual de las intuiciones contrapuestas que parecen coexistir en el definiens aristotélico del alma. a) El intérprete puede obrar sobre el órganon del alma, de manera de atenuar su separación respecto de ésta, diseñando a tal efecto una acepción peculiar del epíteto griego 'organikón'; alternativamente, b) el intérprete puede aceptar sin reparos la caracterización instrumental del cuerpo, pero entendiendo al alma de tal modo, que ella pueda oficiar de actualidad primera a despecho de su separación. La primera línea argumentativa fue adoptada por Alejandro de Afrodisia, quien

quien proporciona un elenco de pasajes). Tracy $(1982,101)$ conjetura que la relativa escasez de referencias al piloto en su función moral de gobernante del cuerpo (cf. Leyes 961d-e) podría deberse a la mayor aptitud de otros símiles para ilustrar la estructura tripartita del alma. Hace notar, en tal sentido, que Fedro 247c reserva únicamente a la parte intelectual del alma, que contempla las Formas, la función de piloto. Con todo, los aspectos morales del símil parecen resonar todavía en los escritos tempranos de Aristóteles. Un empleo elocuente de la figura del piloto en su sentido práctico-moral, todavía indiferente al problema teórico ulterior de la interacción entre substancias, puede hallarse en el Protréptico, donde el filósofo gobierna su propia vida al modo de un navegante que mantiene la vista fija en un firmamento inmutable (fr. B50 DüRING). La conexión entre ambos planos de consideración — psicológico y moral— podría hallarse en el hecho de que tanto el uno como el otro necesitan hacer del cuerpo un instrumento o herramienta del alma: cf. Protréptico B8 y B59 (DüRING).

${ }^{9} \mathrm{El}$ modo en que Le Blond y Ross caracterizan la psicología de Aristóteles (cf. nota 14, infra) es obviamente tributario del trabajo seminal de Nuyens (I948), quien a su vez traspone a los escritos psicológicos del Estagirita el esquema evolutivo diseñado por Jaeger. Cf. Nuyens (1948, 48-51; 245-6), con las observaciones críticas de Lefèvre (1972, 2-25; 77-94) y Menn (2002). Un hábil resumen (y una evaluación crítica) de los principales hitos del enfoque evolutivo de Jaeger en su aplicación a la psicología de Aristóteles durante el siglo xx puede hallarse en Bos (2003, 13-30).

${ }^{10}$ Cf. Metaph. H 6, 1045b5-23. 
procuró eximir al adjetivo 'organikón' de las connotaciones dualistas que normalmente trae aparejadas; la reinterpretación alejandrina fue exitosa, al punto que todavía hoy suele aceptarse como la lectura más natural de esa cualificación en el definiens. ${ }^{11}$ La segunda vía, consistente en (re)elaborar más bien la ontología del usuario que la del instrumento, encontró pleno desarrollo en el ámbito del comentario neoplatónico. Aunque Filópono admitió sin reparos la reforma semántica introducida por Alejandro, ${ }^{12}$ sus esfuerzos (así como los del Ps. Simplicio) se centraron más bien en la reinterpretación de la noción aristotélica de 'actualidad primera', que constituye el otro polo del definiens. Bajo el régimen conceptual neoplatónico, se procuraba mostrar que, sin perjuicio de su separación y subsistencia ontológica, el alma puede oficiar, a la vez, como entelequia inseparable (en algún sentido) del navío que ella ocupa durante su travesía terrena. Nuestra exposición se limitará a reconstruir en sus principales rasgos ambas estrategias exegéticas, procurando subrayar sus respectivos límites.

\section{Barcos sin tripulantes: Alejandro de Afrodisia}

En De Anima 412a26, el alma fue definida como "la realización primera de un cuerpo natural que en potencia tiene vida”. Enseguida, y como si intentase precisar cuál es el cuerpo natural que satisface ese requisito y está en condiciones de vivir, Aristóteles escribe: "pero es de tal índole aquel [cuerpo] que es orgánico" (412b4-6). Ahora bien, como ocurre a menudo en Aristóteles, esta cualificación crucial puede ser tomada de varias maneras, aun cuando esa diversidad de acepciones quede usualmente encubierta bajo la mera trans-

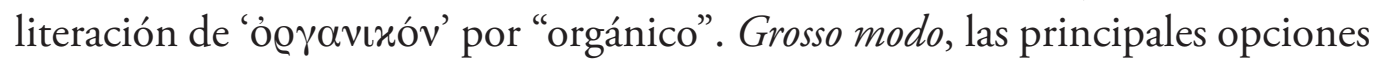
de traducción para 'ỏ $\gamma \alpha v \iota x o ̀ v ~ \sigma o ̂ \mu \alpha$ ' son dos: “cuerpo orgánico”, es decir, "instrumental", por una parte; y "cuerpo provisto de órganos" o "compuesto de órganos", por otra. Esta última opción retrocede al menos hasta Alejandro de Afrodisia (quaest. 54.9-11), quien sostuvo que "lo orgánico es aquello que tiene partes capaces de servir a la ejecución de actividades diferentes, a lo cual juzgó [Aristóteles] que equivalía el 'tener vida en potencia”. ${ }^{13}$ Juan Filópono (a cuyo juicio "es orgánico lo que tiene órganos", 217.13) vio en ese hecho la razón por la cual otros cuerpos igualmente naturales, pero anatómicamente simples (como el fuego), no pueden vivir: pues carecen de partes diferenciadas

\footnotetext{
${ }^{11}$ Sobre la filiación 'alejandrina' de esta interpretación dominante ha insistido justificadamente Bos (1998).

${ }^{12}$ Cf. In De An. 217.12-15.

${ }^{13}$ Quaest. 54.9-11.
} 
a través de las cuales llevar a cabo las funciones propias de la vida. ${ }^{14}$ Esta virtual equivalencia entre diferenciación morfológico-funcional y aptitud para la vida confirmaría la identidad postulada por Alejandro, y autoriza el reemplazo salva veritate de la expresión "cuerpo natural vivo en potencia" por "cuerpo natural

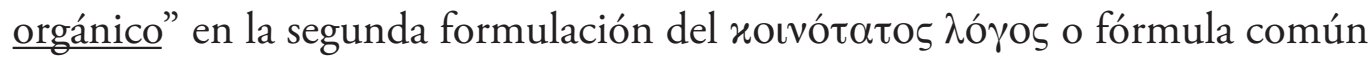
del alma. ${ }^{15}$

Esta interpretación del adjetivo encuentra respaldo en buena parte de los intérpretes modernos, entre los que sobresalen Hicks, Hamlyn y Ross, quienes comprendieron el pasaje tal como antes lo habían hecho Alejandro y Filópono: Aristóteles volvería más precisa su caracterización inicial, al identificar al cuerpo provisto de la potencialidad relevante como aquel dotado de partes orgánicas, lo que hace del alma la actualidad primera "of a natural body furnished with organs for the exercise of its faculties". ${ }^{16}$ Aunque avalada por una

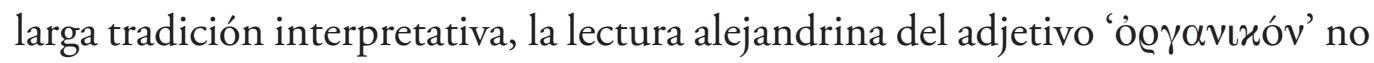
es por ello menos insólita. Como viene siendo advertido de modo creciente en las últimas décadas, ninguna ocurrencia de este término en el corpus aristotélico es portadora del sentido que le atribuyó Alejandro. ${ }^{17} \mathrm{La}$ inflexión semántica sufrida por el epíteto obedece, probablemente, a la dificultad de adjudicarle un sentido preciso cuando éste califica al sustantivo 'cuerpo'. Resulta más intuitivo, en efecto, pensar que éste posee instrumentos o que en todo caso consta $d e$ instrumentos, sin que ello nos comprometa a atribuir al propio cuerpo la condición de un instrumento. Esa incomodidad podría deberse, a su vez, a la dificultad de identificar al usuario correcto de semejante herramienta: si bien las partes instrumentales son órganos del cuerpo, no parece haber algo de lo

${ }^{14}$ Cf. In De An. 217.9-14.

${ }^{15}$ Siempre de acuerdo con Filópono, ambas expresiones son intercambiables y Aristóteles es libre de emplear cualquiera de ellas en lugar de la otra (218.10). Igual opinión en Alejandro, Quaest. 54.9-11 y Temistio (In DA 42.35-37).

${ }^{16}$ Ross (I96I, 20); cf. en igual sentido Hicks (I907, 313). Como observa Menn (2002, 108), es razonable creer que Ross hubiese suscrito de buen grado la equivalencia establecida por

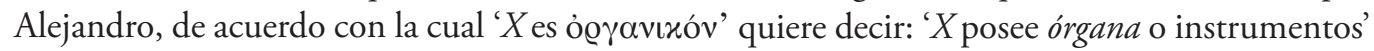
(cf. también Filópono, In De An. 218.3-10). La mutua sustitución de estas dos fórmulas es recomendada expresamente por Bodéüs (1993), ad loc.

${ }^{17}$ Cf. Kosman $(1987,376-7)$, según quien el sentido "ortodoxo" atribuido a este término constituye "a strained reading of organikon, suggesting for it a meaning nowhere else to be found in the corpus". Más recientemente, Everson (I997, 64-5) ha subrayado el empleo consistente que Aristóteles hace del epíteto: "[Aristotle] uses the term to signify that what it qualifies is an organ, and not that it has organs". Sobre tales bases, Menn (2002, 109) define así ese predicado: "an ỏgravıxóv $X$ is an $X$ which is an instrument or is suited for being used as an instrument"; (ver también las persuasivas consideraciones de Bos 2003, 85-94). En nuestra opinión, el punto ha quedado satisfactoriamente establecido por Barnes en su recensión de Everson (I999, 121), quien subraya además la preservación del uso literal (y, con él, del carácter instrumental del cuerpo animal) por parte del Ps. Simplicio: cf. In De An. 87; 90. 29 - 91.4. 
cual el cuerpo pueda ser, a su vez, una herramienta; ${ }^{18}$ pues, en caso de que lo hubiera, ¿quién podría ser el operador de este presunto "órgano global", y dónde habría que "albergarlo"? Dado que a) la idea misma de una 'herramienta' presupone normalmente la distinción real entre ella y su usuario; y que b) la psicología de Aristóteles suele ser vista como una superación de ese dualismo de corte platonizante, parece sensato concluir que la atribución de una naturaleza instrumental al cuerpo traería consigo una recaída en posiciones poco recomendables, que se creía hace mucho abandonadas. Es quizá para eludir ese riesgo que Alejandro operó un desplazamiento sutil en la semántica del adje-

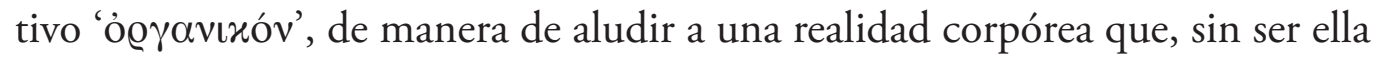
misma instrumental, posee y manipula diversos instrumentos. A falta de ser un órgano en sentido estricto, el cuerpo viviente lo será en el sentido inhabitual de un portador de órganos.

Esta toma de posición anti-platónica explica en buena medida la resistencia a hacer del cuerpo un órgano que pueda caer en manos de un usuario inmaterial y separado, más afín quizá al Fedón que al tratado De Anima. Allí donde la analogía se hace demasiado unívoca y platonizante, siempre cabe acotarla a un período temprano en un esquema preconcebido del desarrollo intelectual de Aristóteles. "La comparación del cuerpo con una herramienta y, por ende, del alma con el operario que la manipula — escribe J.-M. Le Blond, en 1945 - aparece en las obras que Aristóteles compuso cuando aún no se había desprendido del todo de la posición platónica”. Semejante comparación expresaría, por ello mismo, una distinción demasiado taxativa entre alma y cuerpo, a la cual ya no adhiere "el Aristóteles [que] en su vejez escribió el tratado De Anima". ${ }^{19}$ La lectura de algún escrito aristotélico temprano parece corroborar inicialmente ese dictamen. Es así que un fragmento del Protréptico afirma que cada hombre consta de un alma y de un cuerpo a modo de partes, de las cuales una gobierna y la otra es gobernada, de tal manera que el alma utiliza el cuerpo y éste se le subordina como un instrumento (hôs órganon); en efecto, el uso de un instrumento siempre se organiza en vistas del usuario y de quien lo gobierna. ${ }^{20} \mathrm{Si}$ a ello se añade la ausencia en este escrito de ciertas distinciones

${ }^{18}$ Cf. Menn $(2002,110)$. Buena parte de los intérpretes "assume that the parts of an animal's body are órgana of the whole body, so that there would be nothing for the whole body to be an órganon of".

${ }^{19}$ Le Blond (I945, 95-6, n. 80, ad. 642a11). Cf. en el mismo sentido los argumentos de Ross (I955, 16-7), quien ve en la referencia recurrente del tratado De Sensu a "actividades comunes al cuerpo y al alma” un indicio de dualismo substancial, que acreditaría la anterioridad de los Parva Naturalia respecto del libro II del De Anima. Este último suele considerarse como el escrito psicológico más tardío de Aristóteles, y aquel que supera todo rastro de dualismo mediante el recurso a la noción de 'entelequia'. Cf. al respecto las útiles indicaciones de Morel (2000, 22-4).

${ }^{20}$ Protréptico B 59 (DürING). 
conceptuales propias de Aristóteles ${ }^{21}$ y la adopción de algunas características soluciones platónicas, ${ }^{22}$ la homologación del cuerpo con un órganon podría tomarse por un rasgo temprano relativamente excéntrico. Por desgracia, el esfuerzo por relegar la concepción instrumental del cuerpo a un período de inmadurez choca con la presencia de este modelo en el tratado que expresa, de acuerdo con ese mismo esquema evolutivo, la psicología aristotélica madura y más distante de Platón. Ese solo hecho aconseja rehusar la innovación de Ale-

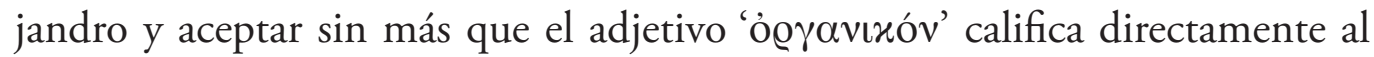
cuerpo, y no de un modo oblicuo, por mediación de las partes instrumentales que 'posee'. El propio cuerpo ha de ser visto, entonces, como un instrumento, aun cuando ello exija reformular en algún grado las nociones de usuario y de instrumento, para acomodar el hecho de su interacción causal. ${ }^{23}$

Un pasaje del tratado sobre las partes de los animales aboga en favor de esta estrategia de lectura. Se trata de un texto que discute, en palabras de Le Blond, "las condiciones que la materia impone a la intención del artesano, y que son a la vez un recurso y un impedimento" para la ejecución de una cierta función (érgon). Allí Aristóteles afirma que "el cuerpo es una herramienta" (tò sôma órganon), pues "cada una de sus partes existe en vistas de algo, tal como el conjunto", lo que trae consigo la elección de materiales apropiados para la ejecución de las "tareas y acciones" con vistas a las cuales dicho cuerpo existe (642a10-13). ${ }^{24}$ Algunas líneas más adelante Aristóteles retoma este paralelismo, recordando que "todo instrumento existe en vistas de un fin": cada parte del cuerpo en vistas de ejecutar una función vital parcial, y el cuerpo en su conjunto con miras a cumplir una actividad multiforme (645b16-17). El punto crucial es que estos y otros pasajes del De Partibus Animalium no admiten ser leídos como fragmentos residuales de un Platonismo que será sobrepasado en el De Anima, puesto que este tratado todavía afirma — con palabras que

\footnotetext{
${ }^{21}$ En particular, la indistinción entre formas del saber que Aristóteles discriminará cuidadosamente en Ética Nicomaquea VI (episteme, phrónesis, sophia).

${ }^{22} \mathrm{La}$ identidad de cada hombre con la parte rectora y racional de su alma, afirmada en Alcibiades 130c1-6 y 133c 1-2, es retomada en Protréptico B62 (DürING). La afinidad de este pasaje aristotélico con la tesis del Alcibiades es advertida también por Denyer (200 I, 234-5).

${ }^{23}$ Rapp (2006, 204-8) observa que, en estricto rigor, la psicología de Aristóteles ha sido cuidadosamente diseñada para evitar los problemas de interacción causal entre componentes psíquicos y corpóreos separados. En tal sentido, su psicología exhibe "a remarkable difference to the discussion of the same phenomena in the Hellenistic schools" (207). La peculiar inseparabilidad conceptual de las afecciones anímicas bloquea ex ante la referencia a estados anímicos "puros", que no estén de antemano implicados en una base fisiológica (cf. DA A 1, 403b17-19; 403b2-3). En tal medida, resultaría impropio decir que tales estados interactúan causalmente con su base material. Sobre los contrastes entre psicología aristotélica y estoica, ver también Boeri (2010, especialmente 55-66).

${ }^{24}$ Cf. también 645b14-22; 646b10 - 647a2; Pol. I 5, $1254 a 34$.
} 
pudieron ser las del Protréptico- que "todos los cuerpos naturales son herramientas del alma, tanto los cuerpos de los animales como los de las plantas, dado que existen en vistas del alma" (415b18-20). La coincidencia literal con lo expresado en el Protréptico ${ }^{25}$ sugiere que el pensamiento de Aristóteles permaneció invariable en este punto.

La inquietud legítima que surge ante la evidencia textual es si esta abierta admisión de la naturaleza instrumental del cuerpo compromete a Aristóteles con un usuario concebido sobre el modelo del piloto en el navío (413a8-9), o con alguna otra versión del sofisma del homúnculo. Dicho de otro modo, se trata de saber si la diferencia entre instrumentos inertes y animados es apenas la que media entre un motor externo al útil, que lo mueve por contacto, y un motor interno que lo pone en marcha al modo del piloto en su navío (413a8-9).

Ciertamente esta dificultad no se plantea a quienes han excluido de entrada la 'instrumentalidad' problemática del cuerpo, apoyándose en la invitación de Aristóteles a desechar, como mal planteada, toda pregunta que inquiera por la unidad de cuerpo y alma (y, en general, de materia y forma en el compuesto sensible: cf. 412b6-9). ${ }^{26}$ En tal sentido, la comprensión del cuerpo orgánico como el usuario de sus propias partes instrumentales ofrece ventajas evidentes, pues desarticula la oposición platónica entre dos substancias, una de las cuales haría de la otra su instrumento. No cabe ignorar, empero, que en el capítulo inicial de De Anima II la dupla 'usuario/instrumento' es al menos tan prominente como el trozo de cera y su figura, lo que torna deseable alcanzar una teoría psicológica en la que ambas figuras del alma puedan coexistir con coherencia. Dicho proyecto exigiría dar con un tipo de entidad que satisfaga las expectativas prima facie incompatibles de ambos modelos psicológicos: el que hace del alma una entelequia y el que la comprende como un artesano "hospedado" en su herramienta. La respuesta más común a este desafío es el escepticismo ante la viabilidad de semejante síntesis. ${ }^{27}$ La razón de fondo es

${ }^{25}$ Protréptico B23 (DüRING).

${ }^{26}$ Esta última es la estrategia adoptada por Nussbaum (I984, 207), quien reprocha al dualista el conceder excesiva importancia a una comparación presuntamente marginal. Semejante intérprete "prefer[s] to hazard his interpretation on a controversial reading of the obscure and altogether aporetic sailor-ship passage from the dialectical first book". Ciertamente Nussbaum tiene en vista $D A$ I 3, 406a5-10, donde la analogía náutica se introduce por primera vez; ella reaparece sin embargo en el libro siguiente (413a8-9), donde adquiere un alcance que excede con mucho lo anecdótico: cf. Polansky $(2007,168)$.

${ }^{27}$ Para una exposición nítida de la disyunción exhaustiva y excluyente entre 'cosa' y 'propiedad' (o 'substancia' y 'atributo'), y de la oscilación inconfortable de la psyché aristotélica entre ambos polos, cf. Granger (1996, 7-8), quien considera empero la posibilidad de un tertium quid que permita describir al alma aristotélica como una suerte de "property-thing" (156-8). Por desgracia, lejos de ser una opción conceptualmente viable, esta posibilidad intermedia "is unintelligible in itself and issues from a confusión in Aristotle's thinking" (156). 
que la disyunción entre "usuario" y "entelequia" se presenta como exclusiva, de manera que ningún término clasificado bajo una de estas rúbricas podría estarlo también bajo la otra: el acto primero de un navío no puede ser a la vez su tripulante, so pena de error categorial.

La opinión según la cual ambos tipos de ítem son incombinables sin contradicción parece haber sido, una vez más, la de Alejandro de Afrodisia, quien rechazó vigorosamente la atribución de funciones vitales a un alma que se serviría del cuerpo como de un instrumento puesto a su disposición. Es así que lo vemos comparar en su De Anima el modo en que el cuerpo viviente actúa por su alma con el modo en que un pugilista maniobra sobre la arena en virtud de las habilidades que ha adquirido. Tales habilidades no combaten en el lugar del púgil,${ }^{28}$ sino que es su cuerpo el que lo hace con arreglo al arte pugilístico, que permanece inactivo. Tal como cualquier otro estado o disposición, el alma no es sujeto de la praxis que despliega el animal por intermedio suyo. Comprenderla de otro modo entrañaría el riesgo de buscar, en la habilidad técnica del pugilista, un pequeńo boxeador agazapado en sus miembros, y que dictaría a aquel sus movimientos sobre el cuadrilátero.

Estas precisiones de Alejandro no son superfluas, ya que apuntan a excluir que el alma se añada al cuerpo como un segundo individuo, capaz de hacer las veces de sujeto alternativo de los predicados que normalmente se atribuyen al compuesto (y de los cuales proporciona Aristóteles una breve lista: "teje", "construye", "se irrita", "compadece", "siente", "se regocija", etc.: cf. $D A$, 408b1-5; b13). Desde esa perspectiva, no sorprende el rechazo que Alejandro opone a la imagen del piloto en el navío. El comentarista no retiene esa comparación más que para alterar radicalmente sus términos y poner, en el lugar del piloto, al arte náutico, sin tolerar intermediario alguno entre éste y el navío: "pero el alma no puede hallarse en su cuerpo a la manera de un piloto en su navío, a no ser que se tomara el piloto como el arte de la navegación" ( $D e$ Anima 15.10-11). Una vez que ha abandonado el astillero, el barco está completo y posee todas las capacidades náuticas que lo hacen eficaz: su perfección no depende de ninguna entidad adicional, que venga a completar a un navío inconcluso. El piloto no será, en consecuencia, la forma y cumplimiento de un navío que en algún sentido requiera de él para llegar a ser. ${ }^{29} \mathrm{Al}$ reformular la analogía en estos términos, Alejandro también la neutraliza.

El rasgo común que estos ejemplos comparten es la reticencia declarada de Alejandro a considerar el alma como siendo a la vez a) el estado de

${ }^{28}$ Cf. Alejandro, De Anima 23.15-24. Este pasaje retoma el célebre texto de Aristóteles, $D A$ A 4, 408b1-18.

${ }^{29}$ Alejandro, De Anima 20.29-30; 23.24 - 24.3. 
acabamiento o completud al que accede un objeto sensible al término de un proceso de generación natural; y b) una substancia independiente, que dispone de este objeto para la ejecución de actividades cuya sede no es el cuerpo que le sirve de instrumento. La segunda opción va de la mano con un cuerpo concebido como órganon del alma, y por ello no es casual que sea Alejandro quien esté en el origen de la interpretación sesgada del adjetivo 'ỏoyavıxóv', que lo atribuye ante todo a las partes corpóreas y solo en sentido derivado al cuerpo mismo. Mediante ese expediente el comentador peripatético bloquea el dualismo substancial que la "instrumentalización" del cuerpo parece traer consigo. Al modelo del artesano experto y del piloto en su navío, Alejandro opone el del púgil que hace uso de sus miembros como de otras tantas herramientas de las que su cuerpo está provisto. Pero ese cuerpo animado es sujeto (y no instrumento) de su propio movimiento: la reformulación alejandrina del tripulante aristotélico lo convierte en un elenco de capacidades náuticas.

Ante ese resultado, algunos notables comentaristas neoplatónicos optaron por distender la disyunción entre usuario y entelequia, cuestionando su carácter excluyente, lo que permitiría al piloto (en palabras de Filópono) "completar la forma de su embarcación aun cuando se encuentre separado de ella". ${ }^{30}$ Como veremos enseguida, esta estrategia neoplatónica — que hace del barco una entidad incompleta, y requerida del piloto para su actualización — goza en la actualidad de un renacimiento moderado, aunque a menudo inconsciente de su filiación.

\section{Tripulantes subsistentes. La estrategia de Juan Filópono}

Lejos de suscribir la disyunción excluyente entre usuario y entelequia que Alejandro hizo suya, Filópono intenta mostrar que un artesano cualificado puede conferir a un instrumento su plena actualidad, comportándose como su causa formal, final y motriz (cf. $D A, 415 \mathrm{~b} 7-12$ ). Para alcanzar esta conclusión no es necesario contravenir el texto de Aristóteles; basta atenerse más bien a una caracterización puramente formal de 'entelequia', como la propuesta por el propio Alejandro de Afrodisia. Según este último, la noción de 'perfección' (teleiótês) contribuye activamente al sentido de la palabra 'entelequia', de manera que todo aquello que encamine a un objeto hacia su propia perfección y lo ponga en condiciones de obrar y padecer según lo que éste es, merece ser llamado su entelequia. Ahora bien, si es verdad que Aristóteles "solía llamar a esta perfección (teleiótês) también 'entelequia', por ser ella la causa de que aquello

${ }^{30}$ Filópono, In DA 224.18-19. 
que la posee haya alcanzado su fin”, ${ }^{31}$ entonces será difícil denegar ese título al artesano en vistas del cual ese útil existe y sin el cual no hubiese sido fabricado. Después de todo, el usuario de una herramienta despliega respecto de ella la triple causalidad que Aristóteles atribuye al alma: ${ }^{32}$ a) el artesano es un "aquello en vistas de lo cual”, en el sentido preciso del beneficiario al cual ese instrumento reporta utilidad; ${ }^{33}$ b) puede ser visto también como el motor, en la medida en que "el movimiento del arte" ${ }^{4}$ no alcanza a la herramienta sin la mediación del artesano que la mueve; por último c) el usuario oficia incluso de causa formal de la herramienta, en la medida en que ésta deriva su función de la producción que contribuye a realizar, de la cual extrae su definición y su substancia en el sentido de 'forma'. Una herramienta queda, en efecto, esencialmente ligada al plexo de útiles del que forma parte y obtiene su ser del modo característico (y parcial) en el que encaja en dicha totalidad, constituida en vistas de una producción. Sin ese contexto, que el artesano encarna, la herramienta cesa de ser un objeto inteligible y arriesga asemejarse a aquellas entidades enigmáticas cuya función no es muy clara - y cuya definición tampoco- 35

No parece imposible, entonces, ver en el piloto, como hace Filópono, el alma y perfección del navío, por cuanto él es "el origen primero de su movimiento local", ${ }^{36}$ así como aquello "en vistas de lo cual" dicho movimiento se ejecuta (pues el piloto es el beneficiario inmediato de una travesía marítima). Aun cuando el capitán de un navío goce de existencia separada e independiente, en algún sentido resultará inseparable de él, ya que su presencia ayuda a definir el barco y hace posible que éste llegue a ser. ${ }^{37}$ De modo análogo, el alma humana es inseparable del cuerpo "en cuanto a las actividades mediante las cuales perfecciona al animal moviéndolo de una u otra manera" ${ }^{38}$

${ }^{31}$ Alexandre, De Anima 16.5-7.

${ }^{32}$ Cf. $D A$ B 4, 415b8-12.

${ }^{33}$ Cf. DA B 4, 415b2-3; 415b20-21. Cf. Metaph. $\Lambda$ 7, 1072 b2.

${ }^{34}$ Cf. GA A 22, 730b22-23.

${ }^{35}$ Cf. Meteorologica $\Delta 12,390$ a14-20.

${ }^{36} \mathrm{DA}$ B 4, 415b21-22.

${ }^{37}$ Así entendida, la entelequia de una cosa va más allá de su función, si es verdad que se vale de esa cosa y la gobierna (kybernâ, 416b26). En un sentido, la vista es acto del ojo, "but is does not guide and use the eye [...] In the same way sailing is the entelechy of a ship. But in a higher sense the sailor, who uses the sailing ship for his own purpose, is the entelechy of the ship", escribe Bos $(2003,128)$. La prioridad causal del usuario naval por sobre el productor de barcos queda bien asentada en Phys. B 2, $194 a 36$ - b8, donde el saber experto de quien utiliza el timón dicta al artesano los movimientos que ha de ejecutar para fabricar un instrumento apropiado.

${ }^{38}$ Filópono, 224.30-31. Sin invocar a este comentador, Robinson $(1983,128)$ adopta la misma opinión: "A boat taken in abstraction from sailors is an essentially incomplete object, its nature cannot be fully stated without bringing in these things. The sailor does, therefore, give the ship its télos and its enérgeia" (cursivas añadidas). 
La reapropiación neoplatónica del concepto de 'entelequia' genera así un resultado imprevisto: en adelante el carácter instrumental del cuerpo, lejos de oponer un obstáculo a la unión hilemórfica, se manifestará como el único modo de facilitar el acoplamiento funcional entre dos entidades substancialmente diversas. Allí donde se acepta sin reparos que alma y cuerpo son dos cosas separadas, cuyas condiciones de persistencia e identidad difieren, solo será posible unificarlas mediante la subordinación instrumental de una a la otra. Es gracias a esa subordinación que las capacidades inferiores del alma racional pueden desplegarse, dado que éstas le pertenecen mientras permanezca unida al instrumento que queda actualizado por ellas. Filópono llega al punto de aceptar que incluso el alma intelectual es "en cierto modo" inseparable del cuerpo, en la medida en que lo actualiza y perfecciona. Por cierto que el capitán no está atado al navío según todo su ser, pero todas sus actividades propiamente náuticas dependen del navío para su ejecución. Resulta hasta cierto punto paradójico que aquello mismo que, a ojos de Alejandro, dificulta la unidad substancial sea aquello que la facilite en opinión de Filópono: en uno y otro caso se trata del carácter instrumental del cuerpo, que si bien instituye un hiato entre cuerpo y alma, ayuda también a colmar esa brecha, al hacer que la coexistencia de uno y otra no acontezca como la mera yuxtaposición de dos substancias inconexas. No sería justo afirmar, por ende, que la posición de Filópono es una instancia de "paralelismo psicofísico", en la medida en que la noción de "instrumento" le permite atenuar un tanto esa distancia substancial y explicar el modo en que las actividades inferiores del alma pueden ser ejecutadas por el cuerpo al que se encuentra unida. Su apuesta parece ser, entonces, que el dualismo substancial es compatible con una suerte de monismo funcional, restringido a un amplio rango de operaciones psicosomáticas de las que solo queda excluida la actividad del intelecto (nôेs). ${ }^{39}$

En consecuencia, Filópono tiene buenas razones para concluir que un único ítem puede ser a la vez una substancia separada por derecho propio y la actualidad de otra substancia diferente, aun cuando se le considere en cada caso bajo formalidades diversas: ya sea en sí misma (hôs ánthrôpos), ya sea en función de las actividades que la vinculan al navío indisolublemente: "inseparable en cuanto a su actividad, pero separable en cuanto a su substancia". ${ }^{40} \mathrm{~A}$ la luz de este análisis, son los propios criterios formales de 'entelequia' aducidos

\footnotetext{
${ }^{39}$ Tanto en sentido literal como metafórico, el piloto anima el navío y actualiza sus estructuras físicas en la medida en que se sirve de él como de un instrumento, pues es entonces que el alma se encuentra más estrechamente unida al cuerpo (cf. FiLópono, In De An. 225.1-4). La independencia ontológica del piloto no hace de él un motor sobreañadido o contra naturam, como temió Alejandro en su De Anima (cf. 15.17-22).

${ }^{40}$ Filópono, 47.28 - 48.2; cf. 224.28 - 225.9.
} 
por Alejandro de Afrodisia los que permiten atribuir a artesanos y pilotos la denominación que Alejandro quisiera denegarles. Retomando los términos de la disyunción exhaustiva y excluyente planteada por Granger, ${ }^{41}$ una cosa puede ser atributo de otra diferente, cuando se la describe bajo el punto de vista de su contribución funcional a esta última. En tal sentido, piensa Filópono, el individuo concreto que gobierna un barco es una entelequia o actualidad primera, cuando se le considera qua piloto y no en cuanto individuo. Esta suerte de "irenismo" psicológico, que logra hacer compatibles las nociones de "usuario" y "entelequia”, posee además la ventaja de preservar su sentido más obvio al epíteto 'ỏ $\gamma \alpha v \iota x o ́ v$ ' en su aplicación al cuerpo, sin necesidad de recurrir a una acepción ad hoc para avalar una interpretación filosófica.

Resulta interesante constatar, por otra parte, que un cierto número de intérpretes contemporáneos ha llegado de modo independiente a conclusiones similares a las de Filópono, sin apoyarse expresamente en la recepción del "cuerpo instrumental” por parte de los comentaristas neoplatónicos. El estudio más reciente del tratado (obra de Ronald Polansky) retiene en sus grandes líneas la estrategia adoptada por Filópono: si se le considera en cuanto hombre, el piloto es una substancia independiente del navío, pero si se le examina en lo que tiene de piloto - esto es, en cuanto encarna el arte de navegar- "quizá no sea separable de él" ("perhaps not separable from it"). ${ }^{42}$ En lo que respecta a Howard Robinson, no parece exagerado afirmar que su estrategia dualista coincide punto por punto con aquella que Filópono o el Ps. Simplicio habían adoptado avant la lettre. La pretendida incompatibilidad "categorial" entre "usuario" y "entelequia" sería fruto de un malentendido, originado en la identificación deficiente de los rasgos relevantes que respaldan la analogía náutica. No es en efecto el hombre en cuanto tal (hôs ánthrôpos, había escrito Filópono) quien vuelve actual el navío, sino el hombre tomado únicamente sub specie nautae: "It is not the man who is a sailor who stands to the boat as form to matter, but the man qua sailor (...) The individual substance, the man, can exist without a boat, but the man qua sailor exists as such only from his relation to the boat." ${ }^{3}$

En tal medida, incluso una substancia separada de este tipo posee rasgos que la vinculan conceptualmente a la embarcación, y en atención a los cuales puede ser vista como inseparable de ella. La coincidencia con la solución de Filópono resulta llamativa.

${ }^{41}$ Granger (I996, 7-8).

42 Polansky (2007, 168-9): "A sailor as sailor belongs in the ship, perhaps not separable from it, directing various aspects of it and thus its actuality, but still with some sort of separateness".

${ }^{43}$ Robinson $(1983,129)$. Por otra parte, esta dependencia es "bilateral", como lo exige el nexo entre material y forma. Dado que las habilidades adquiridas por el navegante solo pueden desplegarse a través de los 'instrumentos de navegación’ de que consta el navío, las partes y piezas del barco "are like the organs of the faculties of the human soul". 


\section{Conclusión. Causas formales y formas motrices}

Juzgada a la luz de su reapropiación neoplatónica, la psicología de Aristóteles parecería decantarse en favor de un homúnculo hospedado en el cuerpo como un usuario inmaterial que lo manipula desde adentro. ${ }^{44}$ Con todo, tiene sentido preguntarse si hay alternativas conceptuales disponibles, que permitan ahorrarle a la psicología hilemórfica de Aristóteles este compromiso con un dualismo substancial. Pensamos que cabe responder afirmativamente a esta pregunta, tomando pie en una sugerencia de Alejandro que hace posible retener el carácter instrumental del cuerpo, sin reintroducir eo ipso una substancia separada a título de "usuario". Como se recordará, Alejandro juzgaba admisible la comparación del cuerpo con una embarcación, con tal de que se concibiese su ocupante conforme al modelo del arte náutico, y no al modo de un artesano portador de capacidades náuticas. Pues bien, hay un elenco consistente de pasajes de Aristóteles que atenúan la incidencia causal del artesano, y que transfieren buena parte de su eficacia motriz hacia las propias formas, concebidas al modo de motores inmóviles. El rasgo común a todos esos textos es la relativa merma del influjo causal de la cadena de motores intermedios. Bajo ese régimen, que acentúa la motricidad de las propias formas, el artesano comparece como una pieza fungible en la cadena causal, cuyo rol se agota en transmitir un movimiento que no es el suyo propio, sino el del arte que modela la materia, y del cual él es portador ocasional. ${ }^{45}$ En ocasiones (como ocurre inter alia en el tratamiento aristotélico de la duplicidad del intelecto humano) se asiste incluso al acoplamiento inmediato de materia y forma, que permite a la receptividad intelectual ser modelada sin intermediarios. ${ }^{46}$ Por razones de espacio, no podemos considerar aquí más que un número reducido de ejemplos textuales.

En De Generatione et Corruptione I 7, Aristóteles afirma que la producción de 'salud' en el enfermo es obra tanto del médico como del medicamento que éste prescribe, el cual actúa como un 'motor movido', pues padece algo a cambio del efecto que produce: "o bien se calienta, o bien se enfría, o bien le ocurre alguna otra afección en el momento mismo en que produce [la salud]" ${ }^{47}$

\footnotetext{
${ }^{44}$ Polansky $(2007,168)$ admite que esta opción deviene especialmente plausible cuando está en juego el alma humana: "The sailor image may fit the unique human soul [...] because only some sort of homunculus suffices for mind".

${ }^{45}$ Como se recordará, lo que hay en los instrumentos, cuando éstos elaboran el producto, es el movimiento del arte y no el del artesano: cf. GA A 22, 730b22-23 (citado en nota 39, supra).

${ }^{46} \mathrm{Al}$ momento de introducir su división entre una inteligencia que produce y otra que padece (DA Г 5, 430 a10-15), Aristóteles recurre nuevamente al modelo provisto por la téchne —con la notable salvedad de que esta vez prescinde del artesano o technites-. Esta omisión del intermediario artesanal es teóricamente significativa.

${ }^{47}$ GC A 7, 324b2-3.
} 
El médico, por su parte, permanece inalterable, al menos en lo que se refiere al saber eficaz que posee —en este caso, el arte terapéutico-, el cual no crece ni decrece por el hecho de ejercerlo sobre el cuerpo del paciente. El terapeuta se comporta así como una especie de motor inmóvil, que induce cambios en otro sin cambiar él mismo. Naturalmente que, para obtener ese efecto, el médico debe desplegar un conjunto de gestos técnicos que involucran el desplazamiento de sus miembros y la alteración de su cuerpo, lo cual parece impedirle obrar al modo de un motor inmóvil. Pese a esta apariencia, la situación del terapeuta es en todo punto comparable a la del albañil impasible que Aristóteles evoca en De Anima II 5, el cual modifica sensiblemente los materiales que están a su alcance, sin verse alterado por ellos; esto es, sin padecer más cambio que la activación de un saber previamente poseído (416b2-3). En esa medida, el albañil es impasible, aun cuando la inmutabilidad aquí aludida sea menos la suya propia que la del arte de edificar, siempre igual a sí mismo y productor de un único efecto. Una vez que se lo ha adquirido definitivamente, el arte permanece inalterable tras cada nueva aplicación. ${ }^{48} \mathrm{Y}$ cabe decir lo mismo del médico que cura: cualesquiera sean los movimientos que ejecute, no experimenta cambio alguno en cuanto a aquella "parte" de sí mismo que produce la salud. Dicho de otro modo: lo que hay de causal y de eficaz en él es inmutable, al punto que en ocasiones Aristóteles atribuirá la curación directamente al arte médico. ${ }^{49}$ Considerados, entonces, desde el saber que poseen, médico y albañil son motores inmóviles: pueden causar cambios precisamente porque en ellos hay algo que no cambia.

Como se recordará, "Alexander of Aphrodisias trie[d] hard to show that the soul is not the entelechy of the body like a sailor of his ship" ${ }^{50}$ Los beneficios teóricos que por esta vía Alejandro obtuvo, en términos de compenetración hilemórfica de cuerpo y alma, arriesgó perderlos en otro frente: el de la eficacia motriz y el influjo causal del alma sobre el cuerpo. ${ }^{51}$ Pensamos sin embargo

${ }^{48}$ Cf. en el mismo sentido Menn (2002, 95-6): "[T] o say that the art is not qualitatively altered in being exercised is also to say that the artisan, qua artisan, is not moved in exercising his art", aun cuando se altere en los demás aspectos de su ser. Empero, no experimentará cambio alguno "in respect of his being a carpenter".

${ }^{49}$ Es lo que ocurre, por ejemplo, en GA I 21, 729b20-21, donde un hijo proviene de su padre de una doble manera: en cuanto este último es su causa motriz y su causa formal, relación de dependencia que también se aplica al convaleciente: el hijo procede del padre "al [doble] modo en que quien fue curado procede de la medicina”.

${ }^{50}$ Bos $(2003,130)$.

${ }^{51}$ Es lo que ocurre, paradigmáticamente, a la interpretación funcionalista de la psicología aristotélica: para ésta, la causalidad motriz de las formas constituye sin duda el escollo más difícil de sortear. El hecho de que una cierta organización o configuración funcional abstracta sea capaz de desencadenar un movimiento resulta implausible, al punto que, como sugiere Cohen (1992, 71-2), "the success of the functionalist interpretation seems [...] to depend on whether the 
que, al aplicar al piloto en el navío el mencionado tratamiento de la causalidad motriz, será posible adoptar la solución de Alejandro, sin que su versión de la analogía náutica nos condene a hacer del alma un motor ineficaz. Como se recordará, el piloto de Filópono podía ser considerado en cuanto hombre -y entonces no era forma ni esencia del navío-, o bien en cuanto portador del arte náutico que hace posible al barco alcanzar su propio fin. Bajo esta última consideración, la humanidad del piloto devenía en cierto modo accesoria y cedía su lugar a la entelequia del barco, de la cual es portador. De cara al navío, el principio motriz relevante no es el que vuelve a su motor humano, sino el que habilita al barco para navegar. Hay un sentido, entonces, en el que cabe decir que no es el hombre emplazado sobre la cubierta el que desencadena la travesía, sino la héxis náutica que éste lleva en su alma y que pone en movimiento sus manos, de manera que éstas guíen el timón. ${ }^{52} \mathrm{El}$ arte mueve las manos y éstas mueven el timón. Es en esta dirección que parece apuntar la reformulación 'alejandrina' de la analogía náutica, que pone la auténtica causa motriz de una travesía en el arte de navegar. Podemos convenir con Filópono en que, si bien el navegante resulta insoslayable para la actualización de un navío aún incompleto, lo que lo vuelve indispensable es su conocimiento náutico.

Es difícil no evocar a ese respecto las observaciones de Aristóteles a propósito de Policleto, que él situó entre las causas accidentales de una escultura, ${ }^{53}$ en la medida en que para ésta resulta irrelevante que el arte de esculpir se halle instanciado en Policleto más bien que en otro artífice que ocupe su lugar. ${ }^{54}$ La observación desconcierta porque insinúa que las obras de un autor están conectadas de modo contingente con su artífice, pues pudieron encomendarse a cualquier otro artesano. Este desconcierto resulta, no obstante, informativo respecto de la noción aristotélica de causalidad motriz, de acuerdo con la cual el artesano "encarna” el arte de manera accidental, porque su téchne es una competencia general que puede hallarse realizada en cualquier otro artesano, con resultados relevantemente similares. Poco importa el nombre del médico que cura, si lo realmente terapéutico es la medicina que reside en él y que está en el origen de su movimiento. ${ }^{55} \mathrm{Al}$ igual que la medicina o la escultura, el arte de navegar es un ejercicio impersonal, cuyos efectos quedan tanto mejor

apparent role of psuchê as efficient cause can be satisfactorily explained away. I am not convinced that it can be". Cf. en el mismo sentido Granger (1996, 129-31).

${ }^{52}$ El proceso es descrito en detalle en GA I 22, 730b15-23; Metaph. Z 7, 1032b10-14; 21-26.

${ }^{53}$ Cf. Phys. B 3, $195 \mathrm{a} 32$ - b1.

${ }^{54}$ Phys. B 3, 195a34-35. Esta convergencia casual del arte y de su portador queda bien reflejada en la versión de la Revised Oxford Translation, que traduce: "because being Polyclitus and a sculptor are accidentally conjoined".

${ }^{55}$ Cf. Metaph. Z 7, 1032b21-26; 1032a22-28. 
garantizados cuanto menos dependen de los manierismos del artífice y cuanto más reflejan los criterios técnicos que rigen toda producción. ${ }^{56}$

Como intuyó Alejandro, las consideraciones generales de Aristóteles relativas a la auténtica causa motriz de un proceso productivo apuntan de modo preferente al arte más que al artesano. Lo causalmente relevante es el arte y no su portador ocasional, aunque éste provea una condición sine qua non. Los motores en cuestión ciertamente son sui generis, pues no entran en contacto con aquello que ellos mueven, al carecer de materia común con sus pacientes: "los agentes que no tienen la misma materia [que sus pacientes] producen permaneciendo impasibles, como es el caso del arte médico" ${ }^{57}$ Es por esta razón que lo afectado por motores de este tipo no puede obrar retroactivamente sobre ellos, ya que ello entrañaría modificar las propias formas, que deben permanecer inalterables en el curso de su transmisión..$^{88}$

Pero si esta interpretación de la causalidad motriz es admisible, Alejandro estuvo en lo correcto al abogar por una reforma del piloto, que permitiese al kybernétês gobernar su cuerpo sin recargar la embarcación con el peso de un tripulante inmaterial suplementario. Al mismo tiempo, es plausible sugerir que Alejandro erró al diseñar una acepción ad hoc de 'ỏ ơovıxóv', cuyo único fin es impedir la intrusión de un usuario independiente que manipule la herramienta corporal como el herrero su martillo. Esa precaución es excesiva, porque la idea de un cuerpo instrumental no necesariamente evoca la de un usuario independiente allí donde el instrumento en cuestión tiene carácter natural (cf. $D A$ 412b5: sómatos physikoû organikoû). En tales casos, dicho "usuario" no es otro que la propia phýsis. Algunos pasajes psicológicos avalan este carácter deflacionario que Alejandro quiso preservar en las herramientas biológicas.

En los procesos físicos, es la naturaleza misma de cada cosa (hê archê hê en hekástôi) la que opera como usuario de los cuerpos y demás útiles orgánicos. ${ }^{59}$

${ }^{56}$ Cf. Metaph. A 1, 981 a5-12; 24 - b6. Aunque trate a Callias o a Sócrates, y no al hombre, que es un universal (cf. 981a18-19), el arte médico no es una mera empeiría, ya que conoce la causa y el porqué (981a29-30). En tal medida, tiene que habérselas con tipos de enfermo y de enfermedad, a los cuales aplica cuidados "estandarizados", con pleno conocimiento de causa. Por cierto, ello no excluye tratamientos "a la medida", pero siempre a partir de una tipología bien establecida.

${ }^{57}$ GC A 7, 324a34-35.

${ }^{58}$ Se comprende, así, la necesidad intrínseca de tales principios motrices en el esquema explicativo de la filosofía natural aristotélica, la cual requiere de motores impasibles que estén en condiciones de desencadenar procesos, sin verse arrastrados por ellos, garantizando así la inteligibilidad del devenir. Solo puede haber cambio en el mundo sublunar porque en el extremo de cada cadena causal hay puntos de partida inmóviles, que dan origen a procesos que en modo alguno los afectan.

${ }^{59}$ Cf. por ejemplo GA I 22, 730b19-23. 
Es a un principio de esta índole, inmanente al organismo, que Aristóteles atribuye el poder de hacer crecer los brotes y de generar continuamente las ramas y las hojas, a medida que otras partes del mismo tipo se marchitan. ${ }^{60}$ Mientras las partes de un insecto que ha sido seccionado sobreviven solamente por un breve lapso, ${ }^{61}$ pues éste se muestra incapaz de generar los órganos necesarios para la preservación de su vida, ${ }^{62}$ cada brote de un vegetal trasplantado hace brotar de sí mismo las partes que le faltan y perpetúa su vida gracias a esa producción. Aristóteles atribuye esta generación de órganos al alma nutritiva de las plantas, cuyo poder "demiúrgico" sobrepasa con creces al poder análogo de los insectos divisibles, incapaces de regenerar sus órganos. ${ }^{63}$ Ahora bien, un principio de ese orden se asemeja menos a un pequeño albañil vegetal, que reconstruye sin cesar la casa en la que habita, que a un poder generador cuyo sujeto es la propia planta. Al mismo tiempo, esta constatación deflacionaria de corte 'alejandrino' no impide a Aristóteles considerar a este cuerpo vegetal como un órganon del alma que lo mantiene en vida, esto es, como el instrumento de un "arte de vivir" que no reside en el artesano o en el piloto tan temidos por Alejandro. Una vez más, el tripulante de esta embarcación no es otro que el propio arte de navegar.

La comparación del alma con una téchnê inmanente al instrumento excluye, de ese modo, toda lectura homuncular y muestra que, para reconocer al cuerpo su índole instrumental, no es preciso contrariar la intuición antidualista expresada en la unidad de la cera con su propia figura. La estrategia alejandrina recién considerada logra hacer un espacio a la relevancia motriz de las formas naturales sin reificarlas indebidamente, ofreciendo respuesta a las inquietudes debatidas en las páginas precedentes.

${ }^{60}$ Cf. De Long. 6, 467a12-18.

${ }^{61} D A$ A 5, 411b22. La disección de anélidos comparece también en A 4, 409 a9-10; A 5, 411b19-27; B 2, 413b16-24; Metaph. Z 16, 1040b10-15; De Incessu Animalium 707a24 - b2; De Iuventute, 468a27-b13; De Long., 467a19; De Partibus Animalium 682b30; De Respiratione, 479a3.

${ }^{62}$ DA A 5, 411b21-24; De Iuv. 2, 468b6-9.

${ }^{63}$ De Long. 6, 467a21-22. 


\section{BiBLIOGRAFÍA}

Balme, D. 1987, "Aristotle's biology was not essentialist", en Philosophical Issues in Aristotle’s Biology, Gotthelf, A. y Lennox, J. (eds.), Cambridge: Cambridge University Press, 291-312. http://dx.doi.org/10.1017/CBO9780511552564.017

Barnes, J. 1994, Aristotle. Posterior Analytics, [Translated with a commentary, Second Edition], Oxford: Oxford University Press.

Barnes, J. I 999, Review of Everson, S., Aristotle on Perception, The Classical Review, 49, no 1: 120-2. http://dx.doi.org/10.1093/cr/49.1.120

Blumenthal, H. J. I968, "Ennead IV.3.20-1 and its Sources: Alexander, Aristotle and Others", Archiv für Geschichte der Philosophie, 50, no 3: 254-61. http://dx.doi.org/10.1515/agph.1968.50.3.254

Blumenthal, H. J. I976, "Neoplatonic Elements in the De Anima Commentaries", Phronesis, 21, no 1: 64-87. http://dx.doi.org/10.1163/156852876X00048

Bodéüs, R. 1993, Aristote. De l'Âme [introduction, traduction et notes], París: Flammarion.

Boeri, M. D. 20 i o, "Ser y géneros del ser en el estoicismo antiguo. Una distinción ontológica importante aplicada a la ética y la teoría de la acción”, Pensamiento, 66, no 247: 55-81.

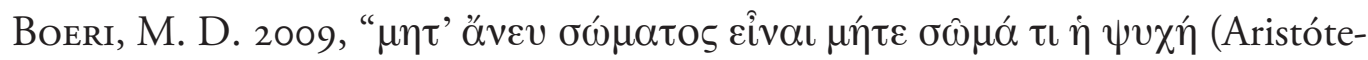
les, De Anima B 2. 414a19-20). A propósito del alcance de las interpretaciones funcionalistas de la psicología aristotélica y del carácter causal del alma”, Elenchos, XXX, no 1: 53-97.

Bos, A. P. 2003, The Soul and Its Instrumental Body. A Reinterpretation of Aristotle's Philosophy of Living Nature, Leiden/Boston: Brill Academic Pub. http://dx.doi.org/10.1163/9789004247635

Burnyeat, M. 2002, “De Anima II 5”, Phronesis, 47, no 1: 28-90. http://dx.doi.org/10.1163/156852802760075693

Caston, V. I999, "Aristotle's two intellects: a modest proposal”, Phronesis, 54, no 3: $199-227$.

Cohen, S. M. I992, "Hylomorphism and functionalism”, en Essays on Aristotle’s De Anima, Nussbaum, M. y Rorty, A. O. (eds.), Oxford: Oxford University Press, 57-73.

Corrigan, K. I999, "Essence and Existence in the Enneads", en The Cambridge Companion to Plotinus, Gerson, L. (ed.), Cambridge: Cambridge University Press, 105-129. 
Denyer, N. 200 I, Plato. Alcibiades, Cambridge: Cambridge University Press. http://dx.doi.org/10.1017/CBO9781139167079

Easterling, H. J. i966, “A note on De Anima 413a8-9", Phronesis, 11, n²: 159-62. http://dx.doi.org/10.1163/156852866X00058

Everson, S. 1997, Aristotle on Perception, Oxford: Oxford University Press.

Gerson, L. 2004, "The unity of the intellect in Aristotle's De Anima", Phronesis, 49, no 4: 348-73. http://dx.doi.org/10.1163/1568528043067005

Gómez-Loвo. A. 2008, "Inmortalidad y Resurrección. Problemas Filosóficos y Respuestas Actuales", Estudios Públicos, 112: 267-84.

Granger, H. I996, Aristotle's Idea of the Soul, Dordrecht/Boston/Londres: Springer. http://dx.doi.org/10.1007/978-94-017-0785-5

Hamlyn, D. W. I 968, Aristotle's De Anima. Books II and III (with certain passages from Book I), Oxford: Oxford Clarendon Press.

Hardie, W. F. R. 1968, Aristotle's Ethical Theory, Oxford: Oxford University Press.

Hartman, E. 1977, Substance, Body and Soul, Princeton: Princeton University Press.

Hicks, R. D. I907, Aristotle. De Anima (with translation, introduction and notes), Cambridge: Cambridge University Press.

Inwin, T. I990, Aristotle’s First Principles, Oxford: Oxford University Press. http://dx.doi.org/10.1093/0198242905.001.0001

Kosman, L. A. I987, "Animals and other beings in Aristotle", en Philosophical Issues in Aristotle's Biology, Gotthelf, A. y Lennox, J. (eds.), Nueva York: Cambridge University Press, 360-91. http://dx.doi.org/10.1017/CBO9780511552564.020

Le Blond, J.-M. I945, Aristote. Parties des Animaux, Livre I (traduction et notes), [Introduction et mises à jour par Pierre Pellegrin, Paris, 1995].

LefÈvre, Ch. I972, Sur L'Évolution d'Aristote en Psychologie, Lovaina: PeetersFrance.

McMahan, J. I999, "Cloning, Killing, and Identity", Journal of Medical Ethics, 25: 77-86. http://dx.doi.org/10.1136/jme.25.2.77

Menn, S. 2002, "Aristotle's definition of soul and the programme of the De Anima", Oxford Studies in Ancient Philosophy, 22: 83-139.

Morel, P.-M. 2000, Aristote. Petits Traités d'Histoire Naturelle (traduction, présentation et notes), París: Flammarion. 
Nussbaum, M. I 984, "Aristotelian Dualism: a Reply to Robinson”, Oxford Studies in Ancient Philosophy, 2: 197-207.

Nussbaum, M. y Putnam, H. i992, "Changing Aristotle's Mind", en Essays on Aristotlés De Anima, Nussbaum, M. y Rorty, A. O. (eds.), Oxford: Oxford Clarendon Press: 27-56.

Nuyens, F. I973, L'Évolution de la Psychologie d'Aristote, Lovaina: Institut supérieur de philosophie.

Polansky, R. 2007, Aristotle's De Anima, Nueva York: Cambridge University Press. http://dx.doi.org/10.1017/CBO9780511551017

Robinson, H. I978, "Mind and Body in Aristotle", Classical Quarterly, 28: 105-24. http://dx.doi.org/10.1017/S0009838800037782

Robinson, H. 1983, "Aristotelian Dualism”, Oxford Studies in Ancient Philosophy, 1: 123-44.

Santa Cruz, M. 1988, Platón. Parménides - Politico, en Platón. Diálogos V. Parménides, Teeteto, Sofista, Político, Madrid: Gredos.

Sellars, W. I967, "Aristotle's Metaphysics", en Philosophical Perspectives, Springfield, 73-124

Rapp, CH. 2006, "Interaction of body and soul: What the Hellenistic philosophers saw and Aristotle avoided", en Common to Body and Soul. Philosophical Approaches to Explaining Living Behaviour in Greco - Roman Antiquity, KING, R. A. H. (ed.), Berlín/Nueva York: Walter de Gruyter, 187-208.

Rodier, G. I900, Aristote. Traité de l'Âme (traduit et annoté), París: Vrin.

Ross, W. D. 1955, Aristotle. Parva Naturalia (a revised text with introduction and commentary), Oxford: Oxford University Press.

Ross, W. D. I96 I, Aristotle. De Anima (edited, with introduction and commentary), Oxford: Oxford University Press.

Tracy, T. I982, "The soul/boatman analogy in Aristotle's De Anima”, Classical Philology, 77, no 2: 97-112.

http://dx.doi.org/10.1086/366689 